\title{
BMJ Open Quality Using Lean tools to improve the efficiency of awake fibreoptic intubation setup
}

\author{
Wade A Weigel (D) , ${ }^{1}$ Andrew B Lyons, ${ }^{1,2}$ Justin S Liberman (D) , ${ }^{1}$ \\ C Craig Blackmore ${ }^{3}$
}

To cite: Weigel WA, Lyons AB, Liberman JS, et al. Using Lean tools to improve the efficiency of awake fibreoptic intubation setup. BMJ Open Quality 2021;10:e001432. doi:10.1136/ bmjoq-2021-001432

- Additional supplemental material is published online only. To view, please visit the journal online (http://dx.doi.org/10. 1136/bmjoq-2021-001432).

Received 22 February 2021 Accepted 9 November 2021

\section{Check for updates}

(c) Author(s) (or their employer(s)) 2021. Re-use permitted under CC BY-NC. No commercial re-use. See rights and permissions. Published by BMJ.

${ }^{1}$ Anesthesiology, Virginia Mason Medical Center, Seattle, Washington, USA

${ }^{2}$ Anesthesiology, Gallatin Valley Anesthesia Associates, Bozeman, Montana, USA

${ }^{3}$ Center for Health Care Improvement Science, Virginia Mason Medical Center, Seattle, Washington, USA

Correspondence to

Dr Wade A Weigel;

wade.weigel@virginiamason.org

\section{ABSTRACT}

Background Awake fibreoptic intubation is a complex advanced airway technique used by anaesthesiologists in the management of a difficult airway. The time to setup this important procedure can be significant which may dissuade its use by some providers. In our institution, the awake intubation setup process was highly variable and error prone.

Methods We deployed Lean methods to improve the efficiency and accuracy of the awake fibreoptic intubation setup process. A 2-day improvement event with a multidisciplinary team addressed the setup process, tested solutions and created standard work documents. Twenty awake fibreoptic intubation simulations were conducted before and after the intervention to quantify gains in setup efficiency and error reduction.

Results Variability in the setup process, including clinical locations visited, was reduced through creating a standardised process. The average time to for an awake fibreoptic intubation setup was reduced by approximately $50 \%$, from 23 min to $11 \mathrm{~min}(\mathrm{p}<0.001)$. In addition, awake fibreoptic intubation equipment set out without error increased in the postintervention simulations from $59 \%$ to $85 \%(p=0.003)$.

Conclusion Using Lean tools, we were able to make the setup of awake fibreoptic intubation not only more efficient, but also more accurate. A similar methodological approach may have value for other complex anaesthesia procedures.

\section{INTRODUCTION}

According to the latest data from the National Center for Health Statistics, 48.3 million ambulatory surgical procedures were performed in the USA in 2010. ${ }^{1}$ Worldwide, more than 300 million surgeries are performed each year. ${ }^{2}$ The majority of these surgeries require general anaesthesia with mechanical ventilation facilitated by the placement of an endotracheal tube, more commonly known as a breathing tube. This process of placing an endotracheal tube, known as intubation, can be accomplished with a variety of methods and special equipment such as video laryngoscopes or fibreoptic bronchoscopes. The standard sequence of placing an endotracheal tube involves rendering the patient unconscious, and apnoeic after which time oxygenation and ventilation using a bag mask is performed. The endotracheal tube is then passed through the vocal cords and secured.

Induction of anaesthesia in a patient with a suspected difficult intubation or difficult mask ventilation may lead to a potentially life-threatening airway obstruction, and repeated attempts at intubation may worsen airway swelling or cause traumatic bleeding, hindering further intubation attempts. ${ }^{3}$ In a retrospective study performed by Kheterpal $e t$ $a l$, performed at four tertiary medical centres showed an overall incidence of difficult mask ventilation combined with difficult intubation of $0.4 \%{ }^{4}$ The alternative approach to the above described conventional intubation strategy is traditionally referred to as awake fibreoptic intubation. Awake fibreoptic intubation involves placing the endotracheal tube in an awake or lightly sedated, spontaneously breathing patient, thereby avoiding mask ventilation prior to intubation. ${ }^{56}$ Awake fibreoptic intubation is classically used in patients who may be difficult to mask ventilate thereby avoiding its attendant risks of inadequate ventilation and oxygenation.

Awake intubation requires the careful balancing of competing goals. Adequate procedural sedation is desired in awake intubations to reduce patient trauma and blunt the gag reflex. However, oversedation may result in patient unresponsiveness and apnoea. Adding to the stress of this complex procedure is the ever-present production pressure faced by the anaesthesiologist. Delaying a case to perform an awake fibreoptic intubation delays subsequent cases. Awake fibreoptic intubations has historically been avoided by some anaesthesiologists for fear of failure, lack of provider experience, lack of equipment availability, potential for a poor patient experience and concern about the time required to setup and perform the procedure. $^{7-10}$ 
Anaesthesiologists at our institution perceived the awake fibreoptic intubation as both difficult and time consuming. In addition, they used their own personal awake fibreoptic intubation techniques, which varied widely in terms of choice of topical anaesthesia, sedation, equipment and technical approach. This interprovider variability culminated in a relatively disorganised awake intubation setup process. Our anaesthesiologists would commonly deviate from a pre-existing institutional awake fibreoptic intubation protocol; they would solicit the aid of an anaesthesia technician to search for and gather their personal list of preferred supplies and medications. There was considerable variability in the places walked to obtain supplies (clinical locations visited). The order of equipment retrieved was also highly variable. Wasted motion and time, as part of the setup process by the anaesthesia technician, contributed to setup inefficiency and served to further deter the use of awake fibreoptic intubation by anaesthesiologists at our institution.

We completed a quality improvement intervention to improve the efficiency and accuracy of the awake fibreoptic intubation setup. Using Lean improvement principles, we sought to develop and implement a setup process that was standardised, transparent, efficient, mistake-free and sustainable. The objective of this paper is to report on this quality improvement project and evaluate its success.

\section{METHODS}

We used the SQUIRE 2.0 quality improvement reporting guidelines. No patients or members of the public were involved in the design or implementation of this quality improvement project.

This project occurred at a 300 bed urban hospital with 28 anaesthetising locations. The department of anaesthesiology consists of 37 anaesthesiologists, 27 anaesthesia residents, 5 anaesthesia fellows, 28 nurse anaesthetists and 16 anaesthesia technicians. Several years prior to the current project on improving awake fibreoptic intubation setup, one attending at our institution developed an evidence-based protocol ${ }^{11-19}$ for the performance of awake fibreoptic intubation. This protocol was rewritten prior to this project with the input of seven attending anaesthesiologists. We felt that this collaborative approach to our evidence-based protocol would yield multiple protocol champions and improve protocol adherence.

Our hospital has over 15 years' experience using the institutional management and quality improvement methodology of the Virginia Mason Production System, an adaption of the Toyota Production System used in vehicle manufacturing. This structured Lean methodology is based on the premise that a process is best redesigned by those who do the work, with improvement interventions designed and implemented through multi-day quality improvement events staffed by representatives of all involved workers. Standardised Virginia Mason Production System tools used in this project included standard work sheet, standard work combination sheet, target progress report, time observation forms and value stream maps (online supplemental figure 1). Value stream maps detail each step in a care process (generated from direct observation of the process), with 'cloud bursts' which represent areas of waste, 'non-value added,' or error which needed improvement. Waste identification and removal is integral to Lean management, with each waste separated into a specific category: time, defects, motion, transportation, inventory, overproduction, processing. Value stream maps serve to define the root cause of a defect and to direct the redesign of the process. Process flow maps were generated to show the physical (or electronic) movement of equipment, staff, supplies, and information at each step in the value stream. Improvement ideas were fleshed out in discussion, then tested on the work floor. The need to test ideas on the work floor cannot be overemphasised, as many great ideas proved unfeasible or involved details not appreciated from a distance. Ideas were adopted only after successful deployment on the work floor using the Plan-Do-Study-Act framework. These Plan-Do-StudyAct cycles occurred throughout our process improvement event. A target progress report was generated after initial measurements were completed to establish goals which included reducing the walking distance (from 367 to 100 steps), reducing the lead time (from 23 to $10 \mathrm{~min}$ ) and aiming to eliminate defects in setup.

We conducted a 2-day 'kaizen' quality improvement event with a multidisciplinary team including primary process participants (anaesthesia technicians), end users (anaesthesia providers and residents), as well as a member who could champion parallel work for an awake fibreoptic intubation and concurrent room turnover (operating room nurse). Each team member contributed ideas. All ideas were vetted with the group to focus on the core opportunities for improvement. The work of the group coalesced around improving and standardising two areas: efficiently building an 'awake fibreoptic intubation pack' containing all the required equipment and delivering the required supplies and equipment when needed at the point of care. During our kaizen event we created a 'value stream map' to document our process for an awake fibreoptic intubation. This value stream map is referred to as our 'current state' and represents our initial understanding of how we conduct awake fibreoptic intubation at our institution. The value stream map would be used during our Plan-Do-Study-Act cycles.

With our first Plan-Do-Study-Act cycle, we focused on building the awake fibreoptic intubation pack, the physical layout of the pack building space, and the movement of the workers. We defined awake fibreoptic intubation pack contents and trialled awake fibreoptic intubation pack building in our anaesthesia supply room. When testing pack building on the work floor, we realised that our original designated space to build the pack was not ideal. Supplies for our awake fibreoptic intubation packs were in three distinct clinical areas. After multiple PlanDo-Study-Act cycles, we created an area where an awake fibreoptic intubation pack could be easily built, with all 
the required supplies in this centralised area. We also designated pack building personnel and arranged for equipment restocking. Ultimately, the awake fibreoptic intubation pack building space contained equipment bins placed in the same order as the equipment listed on the pack building instructions posted on the wall (online supplemental figure 2). We wanted to quantify the time to complete this parallel processing task. Three pack building simulations were conducted over the course of 2 days. It took less than 2 min to build an awake fibreoptic intubation pack (average 1 min $18 \mathrm{~s}$ ).

Our second Plan-Do-Study-Act cycle focused on the improvement of the awake fibreoptic intubation setup and to develop an efficient walking pattern to collect the awake fibreoptic intubation pack, medications required and the fibreoptic scope tower. We surveyed the work area to determine an efficient pattern of equipment collection that would be suitable for any operating room destination for point of care. We created an awake fibreoptic intubation technician instruction sheet which listed equipment acquisition in an order such that technicians who sequentially followed the instructions would naturally fall into the most efficient walking path (online supplemental figure 3). Our intervention resulted in a shorter walking distance and eliminated the tendency to revisit stocking areas.

Delivery of supplies and equipment to the point of care included ensuring that the equipment would be set out in a consistent manner for ease of use. Our third Plan-DoStudy-Act cycle focused on providing a clear visual control for equipment presence and setup. Based on the results of this Plan-Do-Study-Act cycle, we created a watermark on the technician instruction sheet. Equipment laid out on top of the appropriated picture fostered proper equipment setup (online supplemental figure 3). To facilitate long-term adherence to these interventions, we made the instruction sheet readily available in the awake fibreoptic intubation pack by providing printouts inside the awake fibreoptic intubation packs as well as adding the instructions to our departmental website.

Our fourth Plan-Do-Study-Act cycle created an instruction sheet for the anaesthesia provider which was placed at the awake fibreoptic intubation packet building space (online supplemental figure 4). These instructions correlated to the technician instructions, but also addressed timeliness of medication delivery, drug dosing parameters and the steps involved in the actual performance of the awake fibreoptic intubation. Pharmacy preparation of dexmedetomidine required $10 \mathrm{~min}$ of lead time. Accordingly, the first task for providers was dexmedetomidine ordering, but after visualising anaesthesia technician workflow during our Plan-Do-StudyAct cycles, dexmedetomidine retrieval by technicians was placed later in their workflow to allow time for drug preparation. Standardising the provider protocol for an awake fibreoptic intubation had the advantage of making the provider's supply and medication needs more predictable and readily available.
Given the relative infrequency of awake fibreoptic intubation at our institution, it was imperative that we use high-fidelity simulations that closely mirror provider workload to conduct our Plan-Do-Study-Act cycles. The decision to perform an awake intubation is typically made when the anaesthesiologist first meets the patient, immediately prior to surgery. At our institution, anaesthesia technicians gather necessary supplies and equipment, which may include up to 20 distinct items in the case of an awake fibreoptic intubation. These items must be gathered and setup prior to patient transport to the operating room where sedation is started, the airway is anaesthetised and the endotracheal tube is placed via fibreoptic bronchoscopy. Our anaesthesia technicians typically support multiple rooms with varying needs. A request for an awake fibreoptic intubation is prioritised by anaesthesia technicians in our model given the time-sensitive nature of this procedure. Medications for this procedure were located in our automated drug dispensing cabinet (Cerner Automatic Dispensing Cabinets, North Kansas City, Missouri, USA) as well as in the operating room pharmacy.

Twenty awake fibreoptic intubation setup simulations were conducted before and after the quality improvement intervention. The technicians were aware they would be called to simulate an awake fibreoptic intubation setup but were not informed about any details regarding the day, time or location. Each simulation was initiated by placing a Vocera (Vocera Communications, San Jose, California, USA) badge call to an anaesthesia technician. On receiving the call, an observer walked to the technician's location and started timing and documenting the awake fibreoptic intubation setup process. Timing ended when the technician declared the setup was complete. Notes were taken on a time observation form describing when and where the technicians walked (online supplemental figure 5), and the specific activities performed. The process steps taken by the technicians were diagrammed by the observer using a standard Lean work sheet tool. The time to complete a process step was categorised as non-value added time (time spent walking and collecting equipment) or value added time (time spent setting up equipment). A bag of saline labelled 'faux dexmedetomidine' was placed at the pharmacy window to serve as the simulated drug.

Setup accuracy was documented at the conclusion of each simulation using checklists consisting of predetermined items deemed essential for an awake fibreoptic intubation. This checklist was created by conducting a survey of five attending anaesthesiologists. Seven items were chosen for the accuracy checklists, including three items relevant to both the preintervention and postintervention simulations. There were two items specific to the pre-intervention simulations using the original protocol, and two items specific to the post-intervention simulations using the revised protocol. Statistical comparisons in setup accuracy were limited to the three items present in both the preintervention and postintervention simulation checklists. 
Preintervention and postintervention comparisons were made using the chi-square test for proportions and t-test for means. All statistical analyses were performed on STATA V.12.0 (StataCorp). A box plot with medians, IQRs and individual points was created to show the data in comparison to the intervention over time. The timing of simulations was random, reflecting the need for the primary author to conduct simulations during nonclinical time.

\section{RESULTS}

The primary outcomes of this improvement event included eliminating wasted steps for the technician and providing a visual aid when setting up for an awake fibreoptic intubation. The need for standard work was identified and resulted in the technician gaining easy access to the protocol organised to provide a walking path where technicians no longer returned to supply areas multiple times (online supplemental figure 5). The total walking distance was reduced from $1792 \mathrm{ft}$ preimplementation to $657 \mathrm{ft}$ postimplementation, which translates to a $63 \%$ reduction in total feet walked by our anaesthesia technicians (online supplemental figure 5). The visual aid and written protocol standardised equipment setup to make the process streamlined and consistent.

Twenty preintervention simulations were completed using the original awake fibreoptic intubation protocol with 11 different technicians, 9 of whom were timed twice, over the 2 month time frame from May to July 2013. Twenty postintervention simulations were completed using the revised awake fibreoptic intubation protocol with 14 technicians, 6 of whom were timed twice, over the 6-month time frame from August 2014 to January 2015. A box plot shows the awake fibreoptic intubation setup times before and after the March 2014 event (figure 1).

Table 1 summarises the simulation data. In the preintervention simulations, there was an average of 24

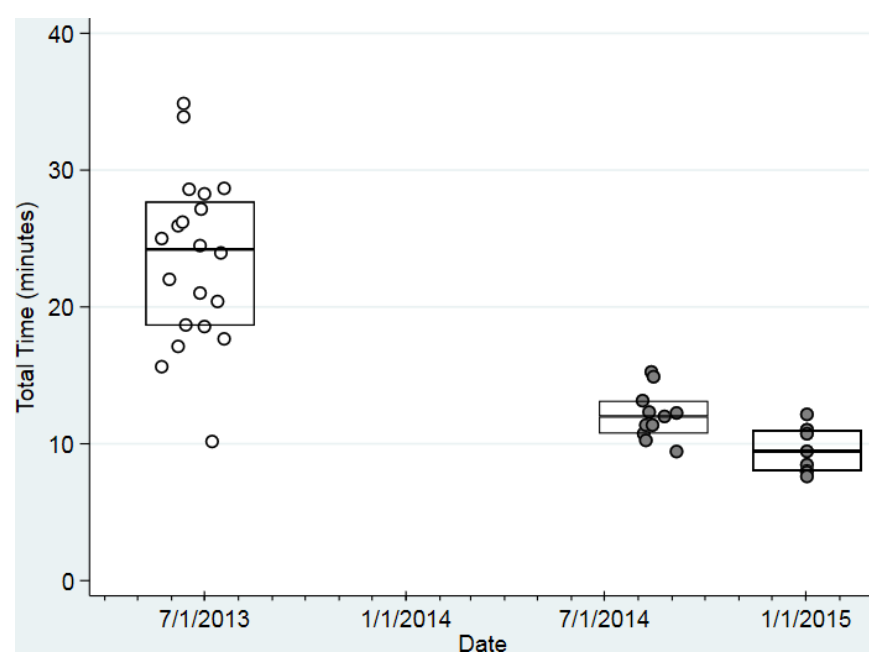

Figure 1 Box plot of the total time to complete AFOI setup before and after intervention. Preintervention median 24.22 (18.63, 27.71) min, postintervention median 11.02 (9.44, 12.20) min. AFOI, Awake Fibreoptic Intubation. process steps by the technicians with considerable variation (13-41 process steps). To compile simulation data, nine common process steps were identified, and the data configured using only those common process steps. After the intervention, there were 13 process steps without variation. Setup time decreased by $12 \mathrm{~min} 26 \mathrm{~s}$ (95\% CI $9 \mathrm{~min}$ $29 \mathrm{~s}$ to $15 \mathrm{~min} 24 \mathrm{~s}$, preintervention $23 \mathrm{~min} 24 \mathrm{~s}$, postintervention $10 \mathrm{~min} 58 \mathrm{~s}, \mathrm{p}<0.001)$. Reduction in the non-value added time accounted for the majority of the overall setup time savings.

Anaesthesia technicians more often correctly set out the three common items post-intervention $(59 \%$ to $85 \%$, difference 26 percentage points, $95 \%$ CI 10 to $43, \mathrm{p}=0.003$, table 2). Error-free setups also increased (18\%-67\%, difference 49 percentage points, 95\% CI 21 to $77, \mathrm{p}=0.003)$. When including items not common to both simulations (total overall correct) there was a more pronounced increase in frequency of items correctly set out (41 percentage points) and error-free setups (61 percentage points, table 2 ).

\section{DISCUSSION}

Through a quality improvement intervention, we were able to standardise the protocol and setup for awake fibreoptic intubation, with decreased awake fibreoptic intubation setup time and reduced equipment setup errors. The overarching lesson learnt from this project was that evidence-based protocols must be made practically sustainable and user-friendly to maintain operating room efficiency, reduce user avoidance and reduce waste. By identifying the shortcomings of the process and then incorporating the expertise of the personnel doing the work during the redesign, we were able to make improvements in setup efficiency and accuracy.

A related critical learning point was that great ideas generated in the classroom required testing. For instance, the idea of building a pack was enthusiastically embraced during idea generation. However, once on the work floor we realised the need for a pack building area near existing supplies, new supply bins, bin restocking arrangements, as well as a storage area for the built packs. The boots-onthe-ground lessons offered by this type of event cannot be realised from a distance.

The need for an awake fibreoptic intubation improvement project was realised during a previous project for organising our difficult airway cart. ${ }^{20}$ During that project, in an effort to reduce unneeded equipment on the unanticipated difficult airway care, the anticipated difficult airway equipment (eg, awake fibreoptic intubation equipment) was removed. That effort led to an $89 \%$ reduction in total pieces of equipment on the difficult airway cart and a $39 \%$ reduction in equipment setup time for an unanticipated difficult airway simulation. An anaesthesia equipment cart project from another institution also used Lean methods, 'voice of the customer,' value-stream map to identify 'non-value added' steps, and spaghetti diagrams, to reduce anaesthesia technician daily walking 
Table 1 Awake fibreoptic intubation simulation data

\begin{tabular}{|c|c|c|c|c|c|c|}
\hline \multicolumn{3}{|c|}{ Preintervention $(n=20)$} & \multicolumn{4}{|c|}{ Postintervention $(n=20)$} \\
\hline \multicolumn{3}{|c|}{ Total process steps: mean 24 , range $13-40$} & \multicolumn{4}{|c|}{ Total process steps: mean 13, range 13-13 } \\
\hline & Common process steps & Time & & Protocol process steps & Time & $P$ value \\
\hline 2 & Retrieve protocol & 00:01:18 & 2 & Collect kit in pre-surgical core & 00:00:07 & \\
\hline 3 & Walk and retrieve dexmedetomidine & 00:00:49 & 3 & Collect lidocaine & 00:00:15 & \\
\hline 5 & $\begin{array}{l}\text { Collect presurgical area equipment and } \\
\text { medications }\end{array}$ & 00:01:06 & 5 & Collect infusion pump & 00:00:15 & \\
\hline 6 & Setup presurgical area equipment & 00:05:53 & 6 & Walk to airway storage area & 00:00:20 & \\
\hline 7 & $\begin{array}{l}\text { Walk to get operating room equipment and } \\
\text { medications }\end{array}$ & $00: 02: 37$ & 7 & Collect fibreoptic tower & 00:00:09 & \\
\hline \multirow[t]{7}{*}{9} & $\begin{array}{l}\text { Set up operating room equipment and } \\
\text { medications }\end{array}$ & 00:07:20 & 9 & Set up equipment & 00:05:22 & \\
\hline & & & 10 & $\begin{array}{l}\text { Walk to operating room } \\
\text { pharmacy }\end{array}$ & 00:00:16 & \\
\hline & & & 11 & Collect dexmedetomidine & 00:00:04 & \\
\hline & & & 12 & Walk to operating room & $00: 00: 18$ & \\
\hline & & & 13 & $\begin{array}{l}\text { Set up dexmedetomidine } \\
\text { infusion }\end{array}$ & $00: 02: 27$ & \\
\hline & Mean setup time & $23.4 \pm 6.2 \mathrm{~min}$ & & Mean setup time & $11.0 \pm 2.1 \mathrm{~min}$ & $<0.001$ \\
\hline & Mean non-value added time & $10.2 \pm 3.6 \mathrm{~min}$ & & Mean non-value added time & $3.2 \pm 0.6 \mathrm{~min}$ & $<0.001$ \\
\hline
\end{tabular}

Many different process steps were observed in the preintervention simulations. Nine common process steps were identified from an overall average of 24 process steps and used to summarise the data. The process steps in the postintervention simulations correlated to the technician instruction sheet. Non-value added time encompassed walking and collecting equipment whereas value added time involved setting up equipment

distance $28 \%$ and significantly reduced the number of callouts in a day. ${ }^{21}$ Our $50 \%$ reduction in awake fibreoptic intubation setup time was comparable to those projects.

The study setting likely had substantial effect on success as this was conducted in an institution with a strong central governance structure built around the Lean methodology of the Virginia Mason Production System. Virginia Mason has deployed Lean as a quality improvement and management method for over 15 years. Initially developed by Toyota to produce automobiles, Lean was adapted to healthcare by Virginia Mason based on a recognition that healthcare is inefficient and fraught with safety and quality errors. All employees at Virginia Mason undergo at least a minimum level of Lean training with leaders and executives receiving more comprehensive experiential training in Lean. In addition to functioning as an improvement methodology through quality improvement events like the one described above, Virginia Mason Production System is also a management system, whereby all daily work and employees, both clinical and nonclinical, are managed using a standard set of Lean tools. This overarching Virginia Mason Production
System approach allows implementation of quality improvement interventions from kaizen events directly into daily management. ${ }^{22-24}$

Sustainability for our improvement project was strengthened by the Virginia Mason Production System. Changes to anaesthesia technician workflow was ingrained in daily ' $5 \mathrm{~S}$ ' (sort, set in order, shine, standardise, sustain), a Lean methodology that ingrains desired behaviours into daily practice. Availability of the awake fibreoptic intubation kits were checked during anaesthesia technician standard work, and visual displays were created to show when supplies were low or went out of stock. Onboarding for new anaesthesiologists, residents and certified registered nurse anaesthetists included a discussion of standard protocols and the awake fibreoptic intubation setup. Our culture of safety at Virginia Mason Medical Center also empowers all individuals to speak up when standard protocols are not being followed, and anaesthesia technicians were integral in helping setup our awake intubations and reminding providers to follow our standardised protocol. 
Table 2 Equipment setup accuracy. Three items common to the pre and post intervention assessments are presented (rows 2-4). Additionally, two items unique to the pre-intervention and two items unique to the post-intervention set up are presented (rows 7-10).

\begin{tabular}{|c|c|c|c|c|}
\hline & Preintervention $\left(n=17^{*}\right)$ & $\begin{array}{l}\text { Postintervention } \\
\left(n=18^{\star}\right)\end{array}$ & Difference $(95 \% \mathrm{Cl})$ & $P$ value \\
\hline $\begin{array}{l}\text { Infusion pump setup with } \\
\text { dexmedetomidine }\end{array}$ & $6 / 17,35 \%$ & $13 / 18,72 \%$ & $37 \%$ (6 to 68$)$ & 0.028 \\
\hline $\begin{array}{l}\text { Atomizer, } 10 \mathrm{~mL} \text { syringe, } 2 \% \text { lidocaine } \\
\text { assembled }\end{array}$ & $12 / 17,71 \%$ & $17 / 18,94 \%$ & $24 \%$ (2 to 48 ) & 0.061 \\
\hline $\begin{array}{l}\text { FOB defogged, lubricated and Parker ETT } \\
\text { loaded }\end{array}$ & $12 / 17,71 \%$ & $16 / 18,89 \%$ & $18 \%$ (8 to 44$)$ & 0.18 \\
\hline Total common items correct & $30 / 51,59 \%$ & $46 / 54,85 \%$ & $26 \%$ (10 to 43 ) & 0.003 \\
\hline Total error-free setups of common items & $3 / 17,18 \%$ & $12 / 18,67 \%$ & $49 \%(21$ to 77$)$ & 0.003 \\
\hline $20 \mathrm{~g}$ PIV, $5 \mathrm{~mL}$ syringe & $5 / 17,29 \%$ & & $\mathrm{n} / \mathrm{a}$ & $\mathrm{n} / \mathrm{a}$ \\
\hline Syringe, $30 \mathrm{~g}$ needle, lidocaine & $3 / 17,18 \%$ & & $\mathrm{n} / \mathrm{a}$ & $\mathrm{n} / \mathrm{a}$ \\
\hline $4 \times 4$ gauze & & $18 / 18,100 \%$ & $\mathrm{n} / \mathrm{a}$ & $\mathrm{n} / \mathrm{a}$ \\
\hline FOB placed at head of OR bed & & $16 / 18,89 \%$ & $n / a$ & $n / a$ \\
\hline $\begin{array}{l}\text { Total overall correct (common and unique } \\
\text { items) }\end{array}$ & $38 / 85,48 \%$ & $80 / 90,89 \%$ & $41 \%$ & $\mathrm{n} / \mathrm{a}$ \\
\hline $\begin{array}{l}\text { Total error free setups (common and } \\
\text { unique items) }\end{array}$ & $0 / 17,0 \%$ & $11 / 18,61 \%$ & $61 \%$ & $\mathrm{n} / \mathrm{a}$ \\
\hline
\end{tabular}

Bold numbers indicate total critical steps and error free setups when only looking at steps common in the pre and post intervention simulations.

*Data were mistakenly not collected for three preintervention and two postintervention simulations.

ETT, endotracheal tube; FOB, fibreoptic bronchoscope; n/a, not available; OR, operating room; PIV, peripheral IV catheter.

A tenet of Lean and other quality improvement methodologies is the need for continuous incremental improvement. For this project, we arbitrarily selected an ambitious target of $10 \mathrm{~min}$ for the awake fibreoptic intubation setup. Despite our substantial gains, and 53\% reduction in setup time, we remain just short of this goal at $10 \mathrm{~min} 58 \mathrm{~s}$. There is opportunity for further incremental improvement in this and all our other processes.

There are limited publications regarding Lean management in the field of anaesthesiology. However, the application of Lean in the perioperative setting offers substantial opportunity as this is a high cost, high utilisation sector of healthcare. ${ }^{25}$ Through the model of awake fibreoptic intubation, we demonstrated improvements in both the efficiency and the accuracy of a complex and timesensitive anaesthesia procedure. The success of this model may be relevant to other applications in the perioperative setting. All institutions vary, and the specifics of our awake fibreoptic intubation setup may not fit at other institutions. However, we believe that the Lean process that we describe will produce more efficient setup idealised to each individual practice setting.

We acknowledge the limitations of this work. Given the logistics of timing a relatively rare event like the awake fibreoptic intubation, simulations were substituted, and we were not able to directly assess for adverse safety events related to the intervention. However, given that the protocol was to standardise a methodology already used at our institution and familiar to our anaesthesiologists, we do not believe there is a significant risk of increased adverse events. Though face-to-face and email communication revealed consistent provider and technician acceptance of the changes made in the awake fibreoptic intubation protocol and setup, there was no formal assessment of this acceptance. Because quality improvement work occurs in the context of an ever-changing work environment, there is always the possibility that measured gains were not due to the highlighted intervention. Potential confounders to our work include a concurrent equipment storage project, a change in the anaesthesia technician workforce, or a change in the operating room infrastructure. None of these conditions occurred during the time of our project. Learning bias could have influenced performance in the second simulations. However, there was an interim change in protocol and equipment setup which would attenuate any learning effect. Additionally, the substantial difference in time from the preintervention to the postintervention simulations argues against learning as a confounder. It is possible that the simpler protocol alone led to a faster and more accurate setup. The elimination of redundancy in places visited argues against this being the sole reason for the gains in efficiency. A reduction in equipment to set out in the revised protocol may also account for the improved accuracy in setup. However, much of the same equipment was used in both protocols. Despite conducting 40 simulations, sample size remains a limitation of this study. 
In summary, through Lean quality improvement efforts, we were able to demonstrate significant improvement in awake fibreoptic intubation setup accuracy as well as efficiency. We feel this work is clinically meaningful because the efficient and accurate setup process for awake fibreoptic intubation allows the anaesthesiologist to focus on performing this complex procedure in a timely manner, and likely confers a patient safety advantage. Though the project targeted only awake fibreoptic intubation, we believe the lessons are applicable to the setup of other procedures in anaesthesia where accuracy and timeliness of setup are critical for safe outcomes.

Twitter Justin S Liberman @JustinLiberman

Acknowledgements Thank you to all the individuals at Virginia Mason who participated in the event and/or provided expert content: Helen A Bean MD, Karen $\mathrm{K}$ Blankenship MA, Robert A Caplan MD, Ruth DiMatteo CER AT, Val Ferris RN, Randy Johnson CER AT, Danielle K Glazier RN, Alison D Hartvigson MD, Robert S Hsiung MD, Sonja Mehta MD, JC Pfeifer CER AT, Stephen M Rupp MD. Thank you to Barbara Williams at the Virginia Mason Center for Health Care Improvement Science for data analysis assistance.

Contributors WAW: This author was involved study design, study conduct, data analysis and wrote the manuscript. This author is the guarantor and accepts full responsibility for the work and/or the conduct of the study, had access to the data, and controlled the decision to publish. ABL: This author was involved study design, study conduct, and editing the manuscript. JSL: This author was involved in writing and editing the manuscript. CB: This author was involved study design, data analysis and edited the manuscript.

Funding The authors have not declared a specific grant for this research from any funding agency in the public, commercial or not-for-profit sectors.

Competing interests None declared.

Patient consent for publication Not required.

Ethics approval This investigation was performed as part of a quality improvement project and a waiver was granted from the Virginia Mason Medical Center Institutional Review Board.

Provenance and peer review Not commissioned; externally peer reviewed.

Data availability statement Data are available upon request.

Supplemental material This content has been supplied by the author(s). It has not been vetted by BMJ Publishing Group Limited (BMJ) and may not have been peer-reviewed. Any opinions or recommendations discussed are solely those of the author(s) and are not endorsed by BMJ. BMJ disclaims all liability and responsibility arising from any reliance placed on the content. Where the content includes any translated material, BMJ does not warrant the accuracy and reliability of the translations (including but not limited to local regulations, clinical guidelines, terminology, drug names and drug dosages), and is not responsible for any error and/or omissions arising from translation and adaptation or otherwise.

Open access This is an open access article distributed in accordance with the Creative Commons Attribution Non Commercial (CC BY-NC 4.0) license, which permits others to distribute, remix, adapt, build upon this work non-commercially, and license their derivative works on different terms, provided the original work is properly cited, appropriate credit is given, any changes made indicated, and the use is non-commercial. See: http://creativecommons.org/licenses/by-nc/4.0/.

\section{ORCID iDs}

Wade A Weigel http://orcid.org/0000-0002-8484-2285

Justin S Liberman http://orcid.org/0000-0002-3151-7438

\section{REFERENCES}

1 Hall MJ, Schwartzman A, Zhang J, et al. Ambulatory surgery data from hospitals and ambulatory surgery centers: United States, 2010. Natl Health Stat Report 2017:1-15.

2 Meara JG, Leather AJM, Hagander L, et al. Global surgery 2030: evidence and solutions for achieving health, welfare, and economic development. Lancet 2015;386:569-624.

3 Benumof JL. Management of the difficult adult airway. with special emphasis on awake tracheal intubation. Anesthesiology 1991;75:1087-110

4 Kheterpal S, Healy D, Aziz MF, et al. Incidence, predictors, and outcome of difficult mask ventilation combined with difficult laryngoscopy: a report from the multicenter perioperative outcomes group. Anesthesiology 2013;119:1360-9.

5 Farag E. Airway management for cervical spine surgery. Best Pract Res Clin Anaesthesiol 2016;30:13-25.

6 Apfelbaum JL, Hagberg CA, Caplan RA, et al. Practice guidelines for management of the difficult airway: an updated report by the American Society of Anesthesiologists Task force on management of the difficult airway. Anesthesiology 2013;118:251-70.

7 Fitzgerald E, Hodzovic I, Smith AF. 'From darkness into light': time to make awake intubation with videolaryngoscopy the primary technique for an anticipated difficult airway? Anaesthesia 2015;70:387-92.

8 Gaba DM, Howard SK, Jump B. Production pressure in the work environment. California anesthesiologists' attitudes and experiences. Anesthesiology 1994;81:488-500.

9 Heidegger T, Gerig HJ, Henderson JJ. Strategies and algorithms for management of the difficult airway. Best Pract Res Clin Anaesthesiol 2005;19:661-74.

10 Li G, Warner M, Lang BH, et al. Epidemiology of anesthesiarelated mortality in the United States, 1999-2005. Anesthesiology 2009;110:759-65.

11 Egan TD, Huizinga B, Gupta SK, et al. Remifentanil pharmacokinetics in obese versus lean patients. Anesthesiology 1998;89:562-73.

12 Hu R, Liu JX, Jiang H. Dexmedetomidine versus remifentanil sedation during awake fiberoptic nasotracheal intubation: a doubleblinded randomized controlled trial. J Anesth 2013;27:211-7.

13 Johnston KD, Rai MR. Conscious sedation for awake fibreoptic intubation: a review of the literature. Can J Anaesth 2013;60:584-99.

14 Kunisawa T, Mitamura S, Hanada S, et al. Ideal body weight-based remifentanil infusion is potentially insufficient for anesthetic induction in mildly obese patients. J Anesth 2012;26:790-3.

15 La Colla L, Albertin A, La Colla G. Pharmacokinetic model-driven remifentanil administration in the morbidly obese: the 'critical weight' and the 'fictitious height', a possible solution to an unsolved problem? Clin Pharmacokinet 2009;48:397-8.

16 La Colla L, Albertin A, La Colla G, et al. Predictive performance of the 'Minto' remifentanil pharmacokinetic parameter set in morbidly obese patients ensuing from a new method for calculating lean body mass. Clin Pharmacokinet 2010;49:131-9.

17 Tsai C-J, Chu K-S, Chen T-I, et al. A comparison of the effectiveness of dexmedetomidine versus propofol target-controlled infusion for sedation during fibreoptic nasotracheal intubation. Anaesthesia 2010;65:254-9.

18 Xue FS, Liu HP, He N, et al. Spray-as-you-go airway topical anesthesia in patients with a difficult airway: a randomized, double-blind comparison of $2 \%$ and $4 \%$ lidocaine. Anesth Analg 2009;108:536-43.

19 Zhang JQ, Meng FM, Xue FS. Is dexmedetomidine or remifentanil alone an optimal sedation scheme for awake intubation? J Anesth 2013;27:627-8.

20 Weigel WA. Redesigning an airway CART using lean methodology. $J$ Clin Anesth 2016;33:273-82.

21 Roberts RJ, Wilson AE, Quezado Z. Using lean six sigma methodology to improve quality of the anesthesia supply chain in a pediatric hospital. Anesth Analg 2017;124:922-4.

22 Clark DM, Silvester K, Knowles S. Lean management systems: creating a culture of continuous quality improvement. $J$ Clin Pathol 2013;66:638-43.

23 Kaplan GS, Patterson SH, Ching JM, et al. Why Lean doesn't work for everyone. BMJ Qual Saf 2014;23:970-3.

24 Kenney C. Transforming health care: virginia mason medical center's pursuit of the perfect patient experience. New York, NY: Productivity Press, 2011.

25 Farrokhi FR, Gunther M, Williams B, et al. Application of lean methodology for improved quality and efficiency in operating room instrument availability. J Healthc Qual 2015;37:277-86. 